\title{
Medical News
}

\author{
Edited by Gina Pugliese, RN, MS
}

\section{New Measures Needed to Protect Blood Supply}

An Institute of Medicine (IOM) committee recently released a report, HIV and the Blood Supply: An Analysis of Crisis Decisionmaking, that said new measures are needed to allow the nation to respond rapidly when the blood supply is threatened by emerging or unknown infectious diseases. The committee based its findings and recommendations on an in-depth analysis of events in the 1980s that led to contamination of the blood supply by HIV. The problems the committee found indicated inadequate institutional decision making and a failure of leadership in 1983 and 1984 that led to less-than-effective donor screening, weak regulatory action, and insufficient communication to patients about the risks of acquiring HIV infection through the blood supply.

The responsibility for safe blood is shared by many diverse organizations, such as the federal government, community blood banks, blood and plasma collection agencies, blood product manufacturers, and the American Red Cross. "The blood safety system works effectively ... to check most threats," said committee chair Harold C. Sox, $\mathrm{Jr}$, chair, department of medicine, Dartmouth Medical School, Lebanon, New Hampshire. "But the events of the 1980 s put the system under much stress ... and the system was unable to deal with a threat characterized by risk and uncertainty. No person or agency was able to develop and implement a coordinated strategy, largely because there was no consensus about the magnitude of the threat and the cost, risks, and benefits of proposed remedies."

The committee's recommendations for achieving a more responsive blood safety system include designation of a blood safety director to lead the government's efforts and a blood safety council to assess threats, devise strategies, and ensure cooperation. The report also calls for a surveillance system at the CDC and a tougher regulatory approach by the Food and Drug Administration when little is known about medical risk.

Each year, approximately 4 million patients are transfused approximately 20 million units of whole blood and blood components. Donor screening, blood testing, and treatment procedures have been stepped up significantly since the advent of AIDS. But the committee noted that consumers have scant legal recourse to address financial hardship caused by illness due to contaminated blood. Most states passed blood shield laws in the 1950s and 1960s that protect blood banks and manufacturers from lawsuits, because these groups provide an inherently risky product that is an essential public service. The committee asked the federal government to consider estab- lishing a no-fault compensation system for those who suffer adverse consequences from the use of blood or blood products.

The committee was not asked to review the current safety of the nation's blood supply. The findings do show, however, that while the system is effective in protecting the blood supply from known pathogens, its principal weakness lies in its ability to identify, and guard against, unknown infectious diseases.

The committee made several recommendations to improve the FDA's regulatory process, such as changing the operation of the advisory committees and proposing a series of "triggers" for taking regulatory or other public health actions to protect the safety of the blood and blood products. For example, when a test or treatment makes a product safer, manufacturers should be urged strongly to withdraw immediately all stocks of untested or untreated products.

The study was funded by the US Department of Health and Human Services. The IOM is a private, nonprofit organization that provides health policy advice under a congressional charter granted to the National Academy of Science. The report HIV and the Blood Supply: An Analysis of Crisis Decisionmaking is available from the National Academy Press; telephone (202) 334-3313 or (800) 624-6242. The cost is $\$ 48$.

FROM: Institute of Medicine. New Measures Needed to Protect US Blood Supply From Future Threats Posed by Infectious Disease. July 13, 1995.

\section{Air Quality During Construction}

Maintaining a safe environment for patients, personnel, and visitors in a healthcare facility is a challenge during periods of construction and renovation. The conference "Health Care Construction and Indoor Air Quality" will be held on November 2-3, 1995, in Bloomington, Minnesota, to address these issues. Cosponsored by the University of Minnesota, American Hospital Association, and American Institute of Architects, the conference is designed for facility planners and building maintenance operation personnel, infection control practitioners, architects, design engineers, commercial and institutional contractors, certified safety professionals, and industrial hygienists.

The purpose of the conference is to assist participants in balancing the need to provide safe conditions during construction with the need to complete projects within budget and time constraints. Topics will include moisture control, air sampling, safety, integrating control strategies and construction scheduling, and remedial actions for problems encountered.

To obtain a conference brochure or additional information, contact Tracey Benson, University of Minnesota, 
405 Coffey Hall, 1420 Eckles Ave, St. Paul, MN, 55108-6068; telephone (800) 367-5363 or fax (612) 625-2207; E-mail tbenson@mes.umn.edu.

\section{Infections Linked to Anesthetic}

The CDC recently reported the results of investigations conducted between June 1990 and February 1993 at seven hospitals following unusual outbreaks of bloodstream infections, surgical wound infections, and acute febrile episodes after surgical procedures. A case-control study identified 62 patients that had an organism-specific infection or acute febrile episode after a surgical procedure during the study period.

Only exposure to propofol, a lipid-based anesthetic agent, was associated significantly with the postoperative complications. In six of the outbreaks, an etiologic agent (Staphylococcus aureus, Candida albicans, Moraxella osloensis, Enterobacter agglomerans, or Serratia marcescens) was identified, and the same strains were isolated from the case patients.

Although cultures of unopened containers of propofol were negative, cultures at two hospitals of propofol from syringes currently in use were positive. At one hospital, the recovered organism was identical to the organism isolated from the case patients. Interview and observation of anesthesiology personnel documented lapses of aseptic technique and multiple opportunities for extrinsic contamination. These included (1) preparation of multiple syringes of propofol at one time for use throughout the day; (2) reuse of syringes or infusion-pump lines, or both, on different patients; (3) use of syringes of propofol that had been prepared up to 24 hours beforehand; (4) transfer of prepared syringes of propofol between operating rooms or facilities; (5) failure to wear gloves during procedures involving touching of the mucous membrane or preparing or administering propofol; and (6) failure to disinfect the rubber stoppers of 50-mL propofol vials before use.

The authors note that despite written recommendations of professional associations such as the American Society of Anesthesiology that specifically advocate the use of aseptic techniques during handling of medications, several reports have been published on poor compliance with aseptic techniques and infection control practices by anesthesia personnel.

Despite earlier reports of propofol-associated outbreaks in the 1990s and the education efforts by the manufacturer, the number of clusters of infections or fever associated with propofol use reported to the FDA rose steadily from 1991 through 1993. The authors suggest that further efforts are needed to reduce the risk associated with propofol use, including increased efforts to educate anesthesia personnel and to restrict propofol access to those educated in its unique properties and handling requirements. The authors note that with the increasing use of lipid-based medications, which support rapid bacterial growth at room temperature, strict aseptic techniques are essential during the handling of these agents to prevent extrinsic contamination and dangerous infectious complications.

FROM: Bennett SN, McNeil MM, Bland LA, et al. Postoperative infections traced to contamination of an intravenous anesthetic, propofol. $N$ Engl $J$ Med 1995;333:147-54.

\section{Hepatitis A From Patient to Staff}

An outbreak of hepatitis A recently was reported in a Florida children's hospital. The case patient, a 14-monthold girl with severe B-cell immunodeficiency, hypogammaglobulinemia, and undiagnosed hepatitis A (anti-HAV negative), transmitted hepatitis A to 26 hospital staff, inpatients, and household contacts via gross fecal contamination from prolonged diarrhea. Infection was proven in the index case by PCR of stool and serum. All infected employees had direct contact with the infected patient, and the greatest risk of infection was for those who handled the source patient's bedpan, diaper, or gown. Glove use was not associated with a decreased risk of infection.

Of the 250 employees tested for hepatitis A virus infection, $60 \%$ were susceptible and had exposure to the suspected source patient. Attack rates ranged from 7\% for physicians to $18 \%$ for nurses. The overall attack rate was $13 \%$ for all hospital staff.

FROM: Burkholder BT, Coronado VG, Brown J, et al. Nosocomial transmission of hepatitis A in a pediatric hospital traced to an anti-hepatitis A virus-negative patient with immunodeficiency. Pediatr Infect Dis J 1995;14: 261-266.

Additional news items in this issue: NIOSH to Issue User Guidelines, page 498; OSHA Updates Free Catalog of Safety and Training Materials, page 502; Increase in Vacomycin-Resistant Enterococci, page 505; Senate Votes on Ryan White Act, page 511; Safety Devices Reduce Injuries, page 517; Rules on HIV Testing of Source Patients, page 525; Hepatitis B Linked to Cryopreservation Tank, page 531 